\section{Life drawing}

Maria Sibylla Merian (1647-1717) was a woman ahead of her time. Born in Germany into a family of artists and engravers, she worked as an illustrator. She is best known for the paintings she made on a trip to Surinam in 1699 . This was well before the more famous male naturalists/explorers such as Charles Darwin and Alfred Russel Wallace travelled the globe, bringing the natural diversity of faroff places to public attention.

Merian was a naturalist from childhood. She made great efforts to depict the life cycle of the animals she drew, often including a key food plant in the picture. The frog illustrated here is from Merian's Drawings of Surinam Insects.

In his Systema naturae, the first taxonomic work describing and naming animal and plant species, Carl Linnaeus mentions Merian's work 136 times.

Two new books tell the story of this remarkable woman. In Die Tierwelt der Maria Sibylla Merian (Basilisken-Presse, €96), Katharina Schmidt-Loske analyses the drawings and watercolours attributed to Merian. Kim Todd's biography Chrysalis (I. B. Tauris, $£ 16.99)$ brings the life and work of Merian to a wider audience.

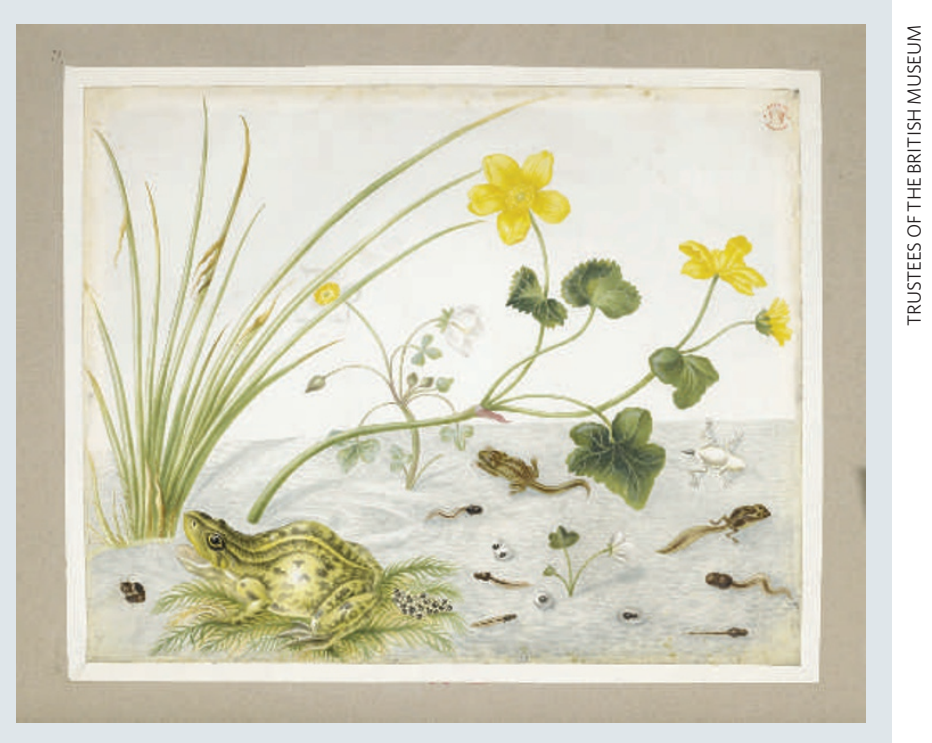

\title{
A better way of thinking?
}

\author{
The Soulful Science: What Economists \\ Really Do and Why It Matters \\ by Diane Coyle \\ Princeton University Press: 2007. 288 pp. \\ $\$ 27.95 / € 17.95$
}

\section{Frances Cairncross}

Alan Blinder, an American economist, once conducted a survey among his friends. He asked them whether there should be one queue in a crowded cafeteria at lunchtime, or two: a fast one for people paying higher prices and a slow one for everyone else. All the economists he knew said two; all the non-economists one. Diane Coyle recounts this telling anecdote in her ambitious book The Soulful Science.

Economists typically see the world through a different lens from most folk. "Economics isn't defined by its subject matter but by its way of thinking," says Coyle. But is it a better way of thinking? She sets out to argue that it is, and that economics has had an unfairly bad press. She comes to her subject from a background as a practitioner rather than as an academic: she has been an economics journalist, runs a consultancy, and has written several books with catchy titles, such as The Weightless World and Sex, Drugs and Economics that make new ideas in economics popular and accessible. Her writing style is clear but sometimes plodding, although she has a good line in anecdotes about the foibles of economists. She describes, for instance, how Joseph Stiglitz, invited to spend a term at the University of Oxford in exchange for eight hours of lecturing, spent one day on a marathon lecture and the rest of the term on his research. As one might say of much in economics - rational but infuriating.

Coyle's defence of her discipline is in some ways the most unsatisfactory aspect of her book. Economists have headed down plenty of blind alleys, and policy-makers have frequently followed them. The first third of the book, devoted to explaining why countries grow and how economic development occurs, contains plenty of examples. One of the most telling chapters describes how economists first provided the justification for massive programmes of development aid — and are now assembling compelling evidence that official aid is either useless as a tool to promote growth or actually harmful.

The critics, Coyle would retort, are often out of date: economics is undergoing a revolution, and becoming a more useful and effective approach to the world. The discipline, she says, is at the threshold of a "golden age", in which many conventional ideas will be overturned. Two changes, little perceived in the outside world, are transforming the discipline. The more important is a revolution in the tools available to economists. We are seeing the creation of a vast number of large data sets, such as figures for historical and cross-country gross domestic product (GDP), and panel studies to track groups as diverse as ethnic-minority children or adults reaching retirement. We are also seeing the development of new statistical techniques and ways to scrutinize the details of economic activity that allow economists to examine more precisely the reasons people make particular choices. And powerful computing has revolutionized economics just as dramatically as other disciplines that rely on gathering and analysing vast quantities of data.

The second change - less important but more interesting to the ordinary reader — has been the willingness of economists to explore and borrow from other approaches to understanding human behaviour. Economists are ransacking psychology, biology and even zoology. Experiments with capuchin monkeys suggest that conventional neoclassical assumptions about the impact of prices on demand apply even in parts of the animal kingdom, reports Coyle. Give monkeys tokens to 'buy' grapes or jelly, and a fall in the relative 'price' of grapes will cause them to buy less jelly and more fruit.

One limitation of such multidisciplinary approaches is that sociology and psychology often take a less rigorously numerate approach to the world, relying on qualities such as 'culture' that are hard to quantify. Economists are getting steadily better at measuring, but still tend to feel that what can't be measured isn't real. But what can be measured, and scrutinized through the unique lens of economics, reveals ever more fascinating perspectives on the world. Books such as Freakonomics by Steven Levitt and Stephen Dubner, or Tim Harford's 'Undercover Economist' column in the Financial Times, draw on the combined revolution in tools and perspectives that is transforming economics.

These arguments are not, however, the book's most impressive achievement. The best thing about it is a deft mapping of the developments in economic thought. Coyle describes brilliantly the intellectual geography of her subject. So anyone who wants to understand how the big ideas of the past half century fit together, and which economists' publications have been key in advancing particular arguments, could not do better than read this book. For a student wondering whether to study the subject, this is the perfect introduction. Although perhaps the basic test for a would-be economist is really very simple: would you prefer your approach to the lunch counter to be rationed by time or by price? One queue or two?

Frances Cairncross is rector of Exeter College, University of Oxford, Oxford OX13DP, UK, and a former journalist on The Economist magazine. 